\title{
Disenchantment and clinical ethics
}

\author{
Henk ten Have ${ }^{1} \cdot$ Bert Gordijn ${ }^{2}$
}

Published online: 1 October 2019

(c) Springer Nature B.V. 2019

In the last century, sociologist Max Weber formulated his famous thesis of the "disenchantment of the world" (Weber 1958, p. 133). With the expansion of modernity, traditional agricultural societies have been replaced by alternative economic and social arrangements. This new social order has encouraged the emergence of a novel type of human being. The historical process studied by Weber has produced an understanding of the world and all areas of human experience that is less mysterious and magical. The world has become knowable and predictable by humans (Weber 1958).

Weber's thesis had profound implications for medicine. He himself referred to medicine as a highly developed practical technology aimed at maintaining life and diminishing suffering. Medical science does not ask whether life is worth living. It tells us what we must do if we want to master life, health and disease but it disregards the question whether it makes sense to do so (Weber 1958).

Disenchantment is visible in medicine in at least two aspects: the emphasis on objectivity, and the impact of bureaucracy and economy. Modern medicine is infused with the ideal of systematic observation, making a clear distinction between objectivity and subjectivity. The basic assumption is that scientific observation is not contaminated by theories, cultural and social context, or subjective biases. Systematic observation therefore is the basis for a scientific approach to medicine (Daston and Galison 2010).

Physicians have to learn how to see the body in a specific and similar way. This way of observing and examining is the result of training and technology, especially visualizing instruments. Michel Foucault has introduced the notion of the 'clinical gaze' (Foucault 1973, p. 85). He argues that in the final part of the eighteenth century a mutation in medical discourse took place, enabling doctors to see what really is the matter with patients. Medicine based on symptoms

\footnotetext{
Henk ten Have

tenhaveh@duq.edu

Duquesne University, Pittsburgh, USA

2 Dublin University, Dublin, Ireland
}

changed into anatomo-clinical medicine-a medicine of organs, sites, and causes. Pathological anatomy became the basis for clinical medicine. Symptoms were explained with reference to lesions in the body. Locating illnesses inside the body, physicians must "abstract the patient": to know the illness, they should relate symptoms to pathological facts (Foucault 1973, p. 8). Pathology provided an objective and real foundation for describing diseases. With this conceptual and methodological approach, medicine transformed into an applied science. The mutation in the conceptual framework of medicine turned the body of a patient into an object of scientific investigation and analysis. The physician should look through the surface into the depth of the body and its tissues. His primary concern is a correct diagnosis. The clinical gaze therefore makes the invisible visible. Clinical symptoms are not the most significant manifestation of illness but refer to lesions. The clinical gaze requires meticulous examination. The doctor is using specific methods such as auscultation and percussion, and finally autopsy, to clarify the underlying pathology. The clinical gaze also requires the collection of written reports, files, documents and records in order to facilitate statistical analyses. The result is that each individual is made into a case of a specific disease (Foucault 1973).

Disenchantment has also affected the discipline of bioethics. One effect of disenchantment is the so-called 'empirical turn' in bioethics during the last two decades. Quantitative and qualitative methods (e.g. case studies, surveys, questionnaires, interviews, and participatory observation) are increasingly used in ethics. The purpose is to obtain empirical information and to map medical reality. The recent upsurge of empirical ethics has several explanations (Borry et al. 2005).

One explanation is the dissatisfaction with the methods of mainstream bioethics. Ethical theories and principles are applied without sufficient attention to the practical realities of health care. Actual experiences and social and cultural contexts are not taken into account.

A second factor is the development of clinical ethics, i.e. the application of ethical analysis within clinical settings with a focus on specific patient cases. Ethics consultation 
begins with an examination of the practicalities of the cases which are emerging in the encounters between patient and healthcare providers. This type of consultation has become a clinical service in many hospitals, especially in the United States and Canada. Consultants can have different backgrounds: medicine, nursing, social work, law, and chaplaincy. The majority are practising healthcare professionals. They are not necessarily experts in ethics. This has raised discussions about professional requirements in terms of qualifications and education (Agich 2013). Against this background, the American Society for Bioethics and the Humanities has launched a Code of Ethics and Professional Responsibilities for Health Care Ethics Consultants based on core competencies. It has also inaugurated a certification and accreditation program for healthcare ethics consulting with examinations and tests (Yarmolinksky 2016; Tarzian et al. 2015). The role of consultants is to assess factual information, to analyse the ethical questions, and to evaluate the outcomes of the consultation. This bedside role is primarily pragmatic, facilitating clinical decision-making. However, there is no agreement on the goals of ethics consultation.

A third explanation for the fast development of empirical ethics is the current emphasis on evidence-based approaches. This has stimulated evidence-based ethics, arguing that ethical decisions should be based on medical scientific evidence, integrating empirical data into ethical decision-making (Major-Kincade et al. 2001).

A final explanation is related to funding of ethics research. In 1990, the Human Genome Programme (HGP) started research activities focused on the ethical, legal and social implications (ELSI) of emerging life sciences. Three percent of the HGP budget (with a projected budget of $\$ 3$ billion over 15 years) was allocated to ELSI which made huge resources available for ethical research. In 1994, the European Union started its own funding initiative, the ELSA program (Ethical, Legal and Social Aspects). This type of research requires that bioethical analysis is combined with empirical and participatory approaches. Empirical evidence is needed to develop policies. Funding of ELSI research seems to promote a research agenda that is empirically driven (Morrisey and Walker 2012).

In the current issue several articles examine clinical ethics. Carter Hardy discusses the role of moral emotions in health care. He criticizes the ideal of detached concern, and thus objectivity, which is promoted as a way to reduce the possible influence of subjective experiences and empathy in the doctor-patient relationship. He concludes that "We need to open medicine to other, supplemental approaches like empathy, sympathy, and care" (Hardy 2019).

This conclusion is important for clinical ethics. However, there are problems in practice, as Dekeuwer et al. (2019) argue in this issue. In France, clinical ethics committees have developed since 1980. But, as the article shows, healthcare professionals do not all work with the same conception of ethics and therefore have different methodological approaches. Another problem is that patients have no role in the committees. The way in which the committees operate have the risk of reinforcing professional autonomy and neglecting the subjective needs of patients.

A further problem is pointed out by Wardrobe (2019). The focus of clinical ethics usually is on individual patient care rather than on social, cultural, economic and environmental ethics. Wardrobe argues that a transition is needed from an anthropocentric to a holistic, biocentric perspective. It is evident nowadays that planetary health is seriously threatened by loss of biodiversity and climate change (ten Have 2019). Wardrope advances several ethical arguments for such transition of bioethical discourse. One of his examples is antimicrobial resistance that is an increasing challenge in clinical medicine. Individualistic approaches will not be sufficient to address this problem, but a wider bioethical view of clinical practice will be needed.

\section{References}

Agich, G.J. 2013. Education and the improvement of clinical ethics services. BMC Medical Education 13: 41.

Borry, P., P. Schotsmans, and K. Dierickx. 2005. The birth of the empirical turn in bioethics. Bioethics 19: 49-71.

Daston, L., and P. Galison. 2010. Objectivity. New York: Zone Books.

Dekeuwer, C., N. Eggert, C. Harpet, and M. Romero. 2019. Falling on deaf ears: A qualitative study on clinical ethics committees in France. Medicine, Health Care and Philosophy 22 (4): 1-15.

Foucault, M. 1973. The birth of the clinic. An archaeology of medical perception. New York: Pantheon Books.

Hardy, C. 2019. Clinical sympathy; the important role of affectivity in clinical practice. Medicine, Health Care and Philosophy 22 (4): $1-15$.

Major-Kincade, T.L., J.E. Tyson, and K.A. Kennedy. 2001. Training pediatric house staff in evidence-based ethics: An exploratory controlled trial. Journal of Perinatology 21: 161-166.

Morrisey, C., and R.L. Walker. 2012. Funding and forums for ELSI research: Who (or What) is setting the agenda? AJOB Primary Research 3: 51-60.

Tarzian, A., L.D. Wocial, and The ASBH Clinical Ethics Consultation Affairs Committee. 2015. A code of ethics for health care ethics consultants: Journey to the present and implications for the field. American Journal of Bioethics 15: 38-51.

ten Have, H. 2019. Wounded planet. How declining biodiversity endangers health and how bioethics can help. Baltimore: John Hopkins University Press.

Wardrope, A. 2019. Does clinical ethics need a land ethics? Medicine, Health Care and Philosophy 22 (4): 1-13.

Weber, M. 1958. Science as a vocation. Daedalus 87 (1): 111-134.

Yarmolinsky, R. 2016. Ethics for ethicists? The professionalization of clinical ethics consultation. AMA Journal of Ethics 18: 506-513.

Publisher's Note Springer Nature remains neutral with regard to jurisdictional claims in published maps and institutional affiliations. 